\title{
Trust-Development in Danish and Norwegian Integration Programmes
}

Tone Larsen, Helse Førde Psychiatric Clinic, Norway

E-mail: tone.larsen@helse-forde.no 


\begin{abstract}
In this article the aim has been to challenge 'integration' as a concept and to explore integration practices in Denmark and Norway. The purpose is to analyse how trust can develop within integration practice. The article is based on a comparison between theories about inclusion/ exclusion, assimilation, integration and trust/distrust, and between the Danish and Norwegian integration practices. These two countries provide an introduction programme, which has been developed as a means to integrate immigrants into the labour market and society. In accordance with these programmes language training, social studies and work practice are provided for mainly non-Western immigrants. However, the comparison between Denmark and Norway shows that the introduction programmes are both similar and different, and in this article the discussion focuses on how these two practices in many ways can be more than simply integrating.
\end{abstract}

\title{
Introduction
}

This article is based on a qualitative comparative study of scientific theories and integrating practices in Denmark and Norway in 2007-2008. The purpose of this study has been to explore perspectives on integration practices and the concept of integration itself. I have therefore compared theories of trust and distrust, assimilation, integration, inclusion and exclusion, in addition to comparing these theories and the integration practices. The aim of this article is to analyse trust development in integration practices based on these theories and the empirical findings obtained by studying the integration programmes in their contexts. The research question throughout the study has been:

What can be learned about integration and trust from a comparison between integration practices in Denmark and Norway?

The two Scandinavian countries have developed introduction programmes aimed at immigrants from non-Western countries. The Norwegian introduction programme derives from the development of the introduction programme in Denmark, so there are many similarities between the two with respect, for instance, language training and social studies, work practice, introduction allowance and individual plans. However, Denmark has developed some of the practices in the programme further than Norway. One example is the integration contract and the declaration of integration and active citizenship in Denmark, as opposed to the individual action plan in Norway. Denmark also has courses for subject specific language training, which were only under discussion in Norway at the time of the study, and there are integration councils in the Danish municipalities.

This article begins with explaining the different theories in use with regards to trust and distrust, assimilation, integration, inclusion and exclusion. An explanation and justification of the research methods is followed by an introduction to the introduction programmes in Denmark and Norway. Finally, I discuss the development of trust in the Danish and Norwegian integration practices, and I have developed Lewicki et al.'s (2006) model of interpersonal trust development further by using the other theories as four corresponding categories. The selections, interpretations and conclusions from the empirical data and literature are my responsibility alone.

\section{Research methods and material}

in 2007 I asked practitioners in the capitals of Norway and Denmark, Oslo and Copenhagen, about their impressions of the introduction programmes (Larsen 2008). I conducted 11 individual semi-structured interviews and led one focus group with persons with particular knowledge about the field of integration. All of the interviews were audio taped. I primarily searched the Internet and the media to find the interviewees. Secondarily, I asked interviewees for advice on 
where to find professionals or organisations that would provide a different view on the integration practices. In addition, I conducted a document analysis of information about the programmes (such as legislation, websites, research articles, media) and of relevant scientific theories.

In Oslo I interviewed a senior adviser at The Directorate of Integration and Diversity at The Ministry of Labour and Social Inclusion, a programme guide at a municipal refugee office, a teacher at a private education centre, an independent integration adviser and a demographer at Statistics Norway. The focus group interview was conducted at The Contact Council Between Immigrants and The Government $(\mathrm{KIM})^{1}$. In Copenhagen the interviewees were a judicial adviser from The Integration Department at The Ministry of Refugee, Immigration and Integration Affairs, a programme guide at the municipal language centre, a teacher and the leader of a private language centre, an integration consultant at a municipal job centre for language and integration, and the vice-chairman of The Council for Ethnic Minorities (REM)².

I used techniques drawn from comparative method when selecting interviewees and relevant documents, preparing the questionnaires, and in the analysing process. According to Peters, the most used method in comparative politics is the Most Similar Systems Design (Peters 1998). Wickham-Crowley's Parallel Demonstration Of Theory strategy (Peters 1998; WickhamCrowley 1991) illustrates this design: In order to control for concomitant variation, one chooses to study a range of countries that appear to be similar in as many ways as possible. Unlike what is done in the Most Different Systems Design, the Most Similar Systems Design does not focus on falsification and on eliminating possible causes for the observed phenomena. In the search for positive relationships the researcher tries to identify many possible causes. However, I could not eliminate any possible causes, since a large number of competing causes would be equally plausible (ibid).

Inspired by Ragin and case-oriented research I have been less concerned with understanding specific outcomes or categories of outcomes (Ragin 1987). Instead, I wanted to determine variance and invariance, so I searched for similarities, deviant cases and influential trends in the Danish and Norwegian integration practices. One of the main reasons for comparing the programmes in Denmark and Norway is the fact that they share a substantial number of common properties, and they appeared to be similar in as many as ways as possible (Peters 1998; Przeworski and Teune 1970, Wickham-Crowley 1991). After all, the Norwegian introduction programme was developed in 2004, and it derives from the practices in the Danish programme that started up in 1999. Furthermore, Scandinavia as a context provides fundamental similarities in history, politics and culture. In fact, Denmark and Norway have comparable histories of immigration: The guest workers immigrated during the 1960s and early 1970s, family reunion boosted after the immigration stop in 1973-75, asylum applicants increased in the 1980s and has decreased through the 1990s, and at the time I conducted the research labour migration was increasing significantly (Hedetoft 2006, Punterwold 2002).

Another important reason for conducting a comparative study in this context is that integration was a highly relevant topic at the time of the study. Denmark amended their integration legislation in 2008, and Norway's legislation on integration was amended in 2007, the Norwegian Foreigners Act was also amended in 2008. My aim was to compare the legislations on integration within their European context. I focused on how the countries influenced each other's integration practices, and on how the legislations were influenced by EU policy, and vice versa. During the period of the study there was also a national election in Denmark, and Norway had a local election. The fact that the Danish government was Liberal Conservative and

\footnotetext{
${ }^{1}$ http://www.kim.no/ : Kontaktutvalget mellom innvandrerbefolkningen og myndighetene

2 http://www.rem.dk/ Rådet for etniske minoriteter:
} 
the Norwegian was Social Democratic made it even more interesting to follow and compare these political developments.

Furthermore, these two welfare states belong, according to Esping Andersen, to the same social democratic welfare regime. In this generous regime the aim is equal opportunities and equal status for everyone, and there is a universalistic ideology that is provided for by state intervention in the form of, for example, taxation and fees (Esping Andersen 1990). Even though the two governments represent opposite political ideologies, figures in the social expenditure ${ }^{3}$ of these countries are in agreement with Esping-Andersen's categorisation at the time of the study. Denmark, Sweden and Norway were in 2007 among the 5 countries that contributed the highest percentages of their GDPs to social expenditures. The fact that the welfare regimes are the same whereas the political environments are very different between these countries, has been an important reason for making the study at hand a comparative study of integration practices.

Finally, in order to challenge the concept of integration I found it revealing to compare theories of trust with theories of integration, assimilation, inclusion and exclusion. This approach made a suitable categorisation available, and it made it clear to me how important trust is in the integration process. Furthermore, by comparing these theories with the empirical data I could challenge the understanding of integration as a concept and also understand the integration practice better. Comparisons between theory-theory and theory-data enabled a deeper understanding of integration, since the theories illuminated my findings and vice versa.

\section{Trust and Integration}

\section{The transformational model}

Lewicki, Tomlinson and Gillespie have organised two approaches ${ }^{4}$ in order to conceptualise and measure interpersonal trust development. In this article I will use the transformational model of interpersonal trust development within the psychological approach when discussing the introduction programmes (Lewicki, Tomlinson and Gillespie 2006). The transformational model shows that time plays a role when trust emerges and develops, and that there are different forms of trust. On the one hand, trust is based on deterrence. For instance, organisations and social groups can, in order to prevent unwanted actions, inform their members in a deterrent way of the negative consequences or sanctions certain actions will lead to. On the other hand, the authors also define 'trust' as 'positive' or 'confident' expectations about another party and a 'willingness to accept vulnerability' in the relationship, under conditions of interdependence and risk' (ibid:1014).

Lewicki et al. illustrate expectations, intentions, affect and dispositions to trust in composite intrapersonal modes in their model: Calculus-Based Trust (CBT) is a concept that has been further developed from what Shapiro et al. (1996) referred to as Deterrence-Based Trust (DBT). In DBT, the importance of keeping one's word is motivated by deterrence. DBT exists 'when the potential costs of discontinuing the relationship or the likelihood of retributive action outweigh the short term advantage of acting in a distrustful way' (Ibid:1006; Shapiro el al. 1996:366). Deterrence prevents and discourages hostile action against the structure and the norms within this system. CBT, like DBT, is grounded in vulnerability to the risks of trusting. However, unlike DBT, CBT focuses on all the benefits of relational interaction.

\footnotetext{
${ }^{3}$ http://epp.eurostat.ec.europa.eu/cache/ITY_OFFPUB/KS-SF-07-099/EN/KS-SF-07-099-EN.PDF

${ }^{4}$ The Behavioural Approach and The Psychological Approach. The Psychological Approach is divided into three conceptualisations: The Unidimensional Model - either you trust or you do not trust someone; The Two-Dimensional Model - trust has a bandwidth, it is possible to both trust and distrust the same person; and finally, The Transformational Model, which illustrates that trust-development can be a dynamic transition.
} 
Lewicki and Bunker defined CBT as 'a ... calculation ... of the outcomes resulting from creating a sustaining relationship relative to the costs of maintaining or serving it' (ibid:1007; Lewicki and Bunker 1995,1996).

Knowledge-Based Trust (KBT) is developed when you show an ability to predict someone's behaviour because you know and understand the other person well. This understanding will improve through reiterated interaction and versatile relationships, resulting in a development from CBT to KBT. When you get to know another person, you learn about the other's reputation, reliability and integrity. Repeated and varied interactions allow one to 'gain more knowledge about the other and engage in activities that generate this knowledge' (ibid:111).

Qureshi's (2005) theory about cultural competence and cultural sensitivity can help us understand the development of KBT better. He suggests two methods for dealing with how majority and minority group members can meet openly: Developing culture competence involves acquiring knowledge about other cultures and being able to see that people living in these cultures benefit from the particular values of this culture. If you are conscious of your own ethnocentrism, you are aware of your tendency to view your own culture as the right one. Consequently, with culture competence, you can see the value of the norms in other cultures. The point is acknowledging and respecting that people have different references, not defining what is best or worst (Qureshi 2005:13).

Qureshi claims that culture sensitivity is a way of understanding others on their own terms. However, there is a difference between understanding and accepting a phenomenon or set of values. The idea of understanding consequences of patterns of thinking and behaviour does not imply indifference. The aim is not to overdo cultural relativism and tolerate everything; it is rather to understand the meaning behind the actions of the person you interact with. Cultural sensitivity is about asking the right questions: What is unique to this culture and what does it have in common with other cultures? (Ibid).

Now, Lewicki et al. argues that KBT can develop into a relationship with strong emotions and identification with the other; it can expand to an Identification-Based Trust (IBT) relationship. Consequently, a transformation of motivation comes to pass in close relationships; the orientation shifts 'from a focus on maximizing self-interest to a disposition toward maximizing joint outcomes' (Lewicki et al. 2006:1009; Kelley 1984). When common products and goals are developed in the relationship, common values are being shared. The persons are located side by side and take on a common name. As these activities increase in frequency and intensity, IBT is developed and strengthened (ibid).

Lewicki and Bunker describe the shifts from CBT to KBT and IBT as a 'frame change' (fundamental shifts in the dominant interpersonal perception paradigm) in the relationship. Emphasis on dissimilarities or differences when comparing oneself and the other, combined with a sensitivity to possible trust violations and to risk, changes into emphasis on assimilation between oneself and others when the trust shifts from CBT to KBT. Additionally, developing the trust into IBT means stabilising commonalities and identities to a balance between strengthening common identities while maintaining one's own distinctive identity in the relationship' (ibid:1012; Lewicki and Bunker 1995,1996). A comparison between this definition of IBT and Qureshi and Hagen's definition of integration shows striking resemblances.

\section{Integration}

Qureshi and Hagen (1996) claim that to integrate means to join, unite or put together into a unit while the unified parts keep their original character. The term is often used concerning the relationship between the minority and the majority population in a society. 'For the minority 
this means the right to preserve qualities from one culture and give up other characteristics, or adopt qualities from the new culture.' (Qureshi and Hagen 1996:16, my translation). Integration is defined as a dynamic process, a reciprocal action between society and diverse social strata, groups and individuals. Ideally, integration means that everyone gets the same chance to influence their environment, and at the same time maintain their identity and integrity. Also, integration should promote development and diversity (Qureshi 1999), and the minorities must have the same rights and duties as the rest of the population. Consequently, integration requires adjustment from both sides, and diversity must be recognised without resulting in suppression, obliteration and subjection. Integrating minority groups into the larger society entails the group members' participation in the majority society's different activities, work, politics and organisations (Qureshi and Hagen 1996:16).

\section{Social inclusion and exclusion}

Carrera et al. (2006) criticise the term 'integration'; they claim that the current understanding of the term fails to agree with the goals of social inclusion and non-discrimination. Instead, this concept of integration is only one-way, and it has become a juridical, policy-oriented and institutional tool for control. It also covers the actual processes of incorporation and assimilation by entailing a state philosophy determining who is included and who is excluded. 'Integration' should rather be replaced by the concept social inclusion since this latter term covers important processes of unequal treatment, discrimination and inclusion tackling exclusion (Carrera et al. 2006:19).

Braeckman illustrates Luhmann's systems theoretical redescription of the inclusion/exclusion debate in modern society:

'Inclusion has to be understood as a form whose inner side (inclusion) is selected as the possibility of social recognition of persons and whose outer side remains unselected. Hence, there can only be inclusion, when exclusion is possible. Only the existence of persons or groups that cannot be integrated reveals social cohesion and makes it possible to specify its conditions.'

(Braeckman 2006:67; Luhmann 1997:620)

Having said that, Luhmann argues that in modern society the situation has changed completely regarding inclusion and exclusion: 'persons do no longer belong to only one subsystem (clan or estate), but participate simultaneously in different subsystems' (ibid:68; Luhmann, 1980:30). Various function domains such as religion, education and profession have developed into definite forms of autonomous subsystems or function systems. In the modern society individuals are defined by which of the various function systems they are included in. This makes career a recipe for societal inclusion that fits perfectly with the modern functional differentiation of society (ibid 72; Luhmann 2000b:302). When workers specialise in certain fields of practice, more of the various consumers' individual needs are met. The different professionals are thereby involved (included) in sustaining and further developing functional differentiation (ibid:69-70; Luhmann 2000c:391).

\section{Assimilation}

Brubaker describes a 'returned' assimilation characterised by a 'direction of change, not a particular degree of similarity' (Brubaker 2001:534). He argues that the understanding of the concept of assimilation has been transformed from a specific and organic sense into a general and abstract sense. Assimilation in the organic sense implies complete absorption, but the abstract understanding of assimilation is 'to become', 'to make similar' or even 'to treat as similar'. Hence, there has been a development from focusing on the final state of assimilation, 
'which suggests state policies and programmes of 'forced assimilation', or at least policies and programmes that seek to assimilate people against their will' (Brubaker 2001:534), to focusing on the process, where assimilation is not an either-or question, but a matter of degree and of increasing similarity or likeness (ibid).

Assimilation has been associated with 'the narrowest understanding of Anglo-conformity or the worst excesses of Americanization campaigns' (Brubaker 2001:534). However, returning assimilation involves a shift from transitive to intransitive understandings. The transitive view sees populations of immigrants as objects that are mouldable and meltable. The intransitive view sees immigrants as active subjects. The assimilation process is not something a government imposes on persons, as Brubaker shows; assimilation is rather accomplished by the persons themselves through making choices in particular social, cultural, economic and political contexts (ibid:541; Alba 1995:4).

Brubaker claims that theorists of assimilation do not simply replicate the pre-1965 approaches. In fact, there have been shifts from thinking in terms of homogeneous units to thinking in terms of heterogeneous units, and from cultural to socio-economic matters. Since the late 1960 s the idea of a universal core culture has lost its plausibility.

'It is no longer true that assimilation (or integration, a term that often, especially in the European context, refers to much the same thing) is 'inevitably' conceptualized as occurring 'into one, single, indivisible (national)'state', and one, simple, unitary (national) 'society'.'

(Brubaker 2001:540; Favell 2000)

\section{Integration Practices in Denmark and Norway}

On the one hand, EU policies have impacts on both Danish and Norwegian immigration and integration practices, even though Denmark is a member of the EU whereas Norway is not. The European Economic Agreement (EEA) opens up the EU labour migration to Norway, and the Schengen Agreement sets standards for both Norwegian and Danish immigration policies (Nugent 2006). Furthermore, the Common Basic Principles for Immigrant Integration Policy in the Hague Programme are mirrored in the integration legislations in Denmark and Norway: Integration must be a two-way process respecting the basic values of the EU: employment; education; equal and non-discriminatory access; basic knowledge of the host society's language, history and institutions; and more (Carrera 2006/1:14. The Danish Integration Act ${ }^{5}$, The Norwegian Introduction $A \mathrm{ct}^{6}{ }^{6}$. On the other hand, Danish integration practice does not only influence Norway, but has also influenced Ministers in the EU to propose the introduction of an EU-wide integration contract? ${ }^{7}$.

\section{Social Democratic vs. Liberal Conservative}

Denmark and Norway are both welfare states in Scandinavia with a history of primarily Social Democratic/Labour Party governance. However, in 2007-2008 the Danish government was a renewed coalition between the Left, Liberal Party and the Conservative Party with support from the Danish Peoples Party (DPP). Immigration and integration had earlier developed into a subject of controversy in Denmark. The unemployment rates and high rates of immigrants in the mid-1980s fuelled a heavy politicisation of the issues throughout the 1990s (Hedetoft 2006). The social and national conservative party DPP promoted the immigrant issue in the media, and it would continue to dominate the electoral campaigns of 1998, 2001 and 2005.

\footnotetext{
${ }^{5}$ http://www.nyidanmark.dk/en-us/legislation/legislation.htm

http://www.ub.uio.no/cgi-bin/ujur/ulov/sok.cgi?type=LOV

${ }^{6} \mathrm{http}: / /$ www.ub.uio.no/cgi-bin/ujur/ulov/sok.cgi?type=LOV

${ }^{7} \mathrm{http}: / /$ www.euractiv.com/en/security/eu-ministers-ask-integration-contract-immigrants/article-153662
} 
In 2001 promising tighter immigration controls in the wake of the 11 September attacks on USA proved to be a well-timed move in the Danish general election (Hedetoft 2006). As a result prime minister Anders Fogh Rasmussen became the first Danish liberal leader to be re-elected in 2005 and $2007^{8}$. Besides promising an end to indulgent policies on immigration, the L-C government promised stricter controls and tougher policies. Consequently the government was supported by the DPP in $2002^{9}$ when passing a legislative 'package' on immigration and integration. The principal intention of the Immigration and Integration law package was restricting access, introducing tougher requirements, ensure the loyalty of newcomers to 'Danish values' and to speed up the integration of immigrants into the labour market (ibid).

In Norway the government was in 2007-2008 a coalition between the Labour Party, the Socialistic Left and the Centre Party. The present government has since $2005^{10}$ been the majority coalition known today. Labour Party leader Jens Stoltenberg was in 2007 in his second period as Prime Minister. The strongest party in opposition to the Social Democratic government is the Liberal Progress Party, which is liberalistic. According to Statistics Norway's (SSB) report on governmental elections the last decade, the Liberal Progress Party was at its peak with $22.1 \%$ of the votes in $2007^{11}$. The party has argued in favour of developing stricter immigration policies and restricting immigrants' rights ${ }^{12}$. For instance, they wished to introduce the Danish 24 years age limit ${ }^{13}$ in addition to a tight connection-demand when working on the new Norwegian Foreigners Act (Dagbladet 10.06.07). Another example of their wish to restrict access was their proposal to test potential immigrants' aptitude for being integrated abroad (Dagbladet 11.10.06). In the local election in 2007, and reminiscent of the Danish electoral debates, the leader of the Liberal Progress Party also claimed, that her party wanted to end the indulgent policies on asylum, and appealed for more restricted and just immigration policies (NRK 08.09.07: Valg 07).

\section{The introduction programmes in Denmark and Norway}

The two introduction programmes are mandatory, and they are regulated by the Danish Integration Act and the Norwegian Introduction Act, respectively. The local councils in Denmark are, according to the Integration Act, responsible for the common integration effort ${ }^{14}$ : housing refugees and the introduction programme; Danish lessons; activation; the integration contract and the declaration of integration and active citizenship in Danish society; and the introduction allowance (Integration Act 2008 Chap. 3, §§ 1-4, 16-32). The integration effort also involves encouraging citizens, enterprises, the authority, administrations, institutions, organisations, unions and others to contribute to the integration process. In Norway the municipalities also have these responsibilities. The Introduction Act aims 'to increase the possibility of newly arrived immigrants participating in working and social life and to increase their financial independence' (Introduction Act $\$ 1,2007$ ). This act is for the most part concerned with the introduction programme, Norwegian language training, social studies, preparing the participants for further education or access to working life, the individually adapted plan, and the introduction benefit (\$2-16).

\footnotetext{
8 http://jp.dk/arkiv/?id=1140937\&eceExpr=Fogh\%20Rasmussen\%20til\%20valg\&eceArchive=0 :

9 www.danskfolkeparti.dk/ldeologies.asp. My interpretation.

10 In 2001-2005, the Christian Conservative Party cooperated with the Conservative Party and the Liberal Party. http://www.vg.no/nyheter/innenriks/artikkel.php?artid=199324: This government was among other things known for restricting the asylum policy.

${ }^{11}$ www.ssb.no

12 http://www.frp.no/Innvandringspolitikk.d25-TgZfSOc.ips

13 The Danish L-C government introduced the '24 year rule' with support from the Social Democrats. This is an age limit for family reunification. It is prohibited for any Danish citizen to marry nationals from outside EU and the Nordic countries unless both parties are more than 24 years old.

${ }^{14} \mathrm{http} / / / w w w . n y i d a n m a r k . d k / e n-u s /$ Integration/a_comprehensive_integration_initiative/ a_comprehensive_ integration_initiative.htm
} 
In both countries, the legislation on immigration regulates the right to participate in the introduction programme. The Integration Act applies to refugees and immigrants lawfully residing in Denmark (Integration Act \$2. 2008). In Norway the right and obligation to participate in an introduction programme applies to newly arrived foreign nationals who have been resident in a municipality for less than 2 years. The foreigners must have been granted asylum or a residence or work permit after being given leave to enter the country as a resettlement refugee. Foreigners with a renewable residence or work permit based on an application for asylum, or with collective protection in a situation of mass outflow, can also participate in the introduction programme. Finally, foreigners with a residence or work permit as members of the family of such persons as the ones mentioned above can participate (Introduction Act $\$ 2,2007)$. The integration legislation does not apply to Nordic and EU citizens and foreign nationals in the EEA. Nationals from EU/EEA member states and Switzerland, however, are allowed to participate in the Danish Language courses for a fee. The Norwegian language schools also offer language training and social studies for a fee ${ }^{15}$.

In Norway, the right and obligation to free language- and social training differs from the right and obligation to participate in an introduction programme. This training applies to foreigners between 16 and 55 years of age and who have been granted residence or collective protection, or who possess a work permit (ibid §17). The right and obligation to participate in the Danish introduction programme encompasses foreigners older than 17 years, and the municipality may offer the whole programme to unaccompanied minors. According to the Norwegian act foreigners are only obliged to participate in the whole programme if they are between 18 and 55 years. Foreigners between 55 and 67 years with residence or work permit may, but are not obliged to, participate in language training and social studies. Foreigners between 16 and 18 are also obliged to participate in this training. Persons under 16 can attend 'reception classes' in primary school and receive basic language training before they join an ordinary class ${ }^{16}$.

The local councils in Denmark must make sure that the immigrants they have taken responsibility for start the introduction programme within one month; in Norway the time limit is three months. The Danish introduction programme lasts for three years, and for those who are entitled to the introduction allowance the programme must have a scope of at least 37 hours per week on average, including preparation (Integration Act $\$ 16.2008$ ). The Norwegian introduction programme shall run for a full year on a full-time basis, which is $37 \mathrm{l} / 2$ hours a week (\$4-2), including $71 / 2$ hours a week for preparation and self-tuition (Kavli and Djuve 2007:48). The programme may run for up to two years, and it may also run for up to three years when special reasons justify this (\$5).

The Norwegian language training and social studies are free of charge for a total of 300 hours (§17). The 50 hours on Norwegian society are included in the 300 hours, and as in Denmark, these lectures are given in a language the participant understands. Further free Norwegian language training can be offered for up to a maximum of 2,700 hours. This municipal obligation applies for five years from the date the right or obligation to participate arises. As in Denmark 'the training shall be provided by the municipality or by others approved by the municipality' (Integration Act §18. 2008). The Norwegian language training is structured in a way similar to the Danish language training. The training is built up in three traces ${ }^{17}$ or levels. The language training in trace one is designed for illiterates, trace two for those who already have some schooling and know the Latin alphabet, and trace three for people with good education, including those with Western education.

\footnotetext{
${ }^{15}$ http://www.oslovo.no/content/view/113/237/

$16 \mathrm{http}: / /$ www.velkommenoslo.no/english/norwegian/right.htm

17 http://www. lovdata.no/for/sf/kd/xd-20050916-1055.html
} 
In addition to the lessons in Danish language (Integration Act \$21-22. 2008), the programme also includes activation in the shape of guidance and qualification. In order to gain a social understanding, the participants are offered short guidance- and clarification courses and ordinary education. Special qualifying courses are also offered, the objective of which is application to education and the labour market. Finally, particularly adjusted projects and education courses are provided through college, practice during education and subject-specific Danish training. In fact, the municipal language schools in Copenhagen offer what KIM criticised Norwegian language schools for not providing, namely subject-specific language training.

The Danish programme guide pointed out that those who are entitled to introduction allowance are offered special language training in subjects like transportation, restaurant and service, social and health, and paedagogy at the Municipal Language Centre. However, the Danish integration consultant pointed out that since most have been admitted into Denmark on breadwinner terms, only $4 \%$ of the participants in the introduction programme receive the allowance. She pointed out that since only a few have the access to subject-specific language training, there is a need for courses that qualify for certain fields in the labour market aimed at all immigrants. Having said that, the objective of the subject-specific language training at a municipal language centre is to provide narrow subject knowledge, to practice skills and to develop social and cultural competence useful in work situations. These courses combine regular Danish training, social studies, and activation. Furthermore, in order to train and practice professional, social and linguistic skills, foreigners are offered work practice (maximum 26 weeks), and employment with wage-subsidy (maximum 1 year) (ibid \$23-23a-e).

According to Djuve work practice places are the most commonly used strategy for integrating individuals into the labour market. The wage subsidies, training and practice places are nonWestern immigrants and Norwegians passages into the labour market. The work practice in Norway can last for 10 months for ordinary job seekers, and 3 years for persons who have labour restraints. Furthermore, the participants get work training based on goals agreed upon by the participant and the employer. The intention is for participants to try out their possibilities in the labour market, and improve their opportunities to get a job or start an education (Djuve 2007:15).

In Denmark foreigners who are not entitled to introduction allowance will only be offered Danish lessons. However, the local council may offer the whole programme to others, except support for mentor-functions at the workplace, in education, or in work practice (\$23d). In addition, subsidies for expenses in relation to guidance and qualification (23e) are not offered to participants without the allowance. While in the Danish Act there are regulations on subsidies and assistance in special cases (chapter 6), the Norwegian Act deals with the right to and calculation of the introduction benefit. In Denmark the introduction allowance is the same as start allowance (Integration Act §27. 2008).

Only persons who have lived outside Denmark in seven out of the last eight years are eligible for the start allowance. Persons who have lived in Denmark for the last seven years are entitled to a cash allowance, which is twice the size of the start allowance and equivalent to the Norwegian introduction benefit. The monthly integration allowance was intensely debated in 1999 since it was so much lower than the corresponding welfare benefits (Hedetoft 2006). In fact, The United Nations High Commissioner of Refugees regarded the allowance as violating the international refugee conventions, and asserted immigrants were unequally treated and negatively discriminated. The government subsequently withdrew the section of the act that dealt with this allowance. Nevertheless, when the L-C government took office it was implicitly included in the act, although this time they created a $\$ 27$, asserting that the introduction allowance corresponds to the (new) start allowance. Furthermore, the terms for the start allowance were articulated in such a way that Danish citizens would also risk getting this lowest welfare benefit (ibid). 
The introduction allowance in Norway can be had for 3 years, and only aliens who do not have a reasonable work offer are given this right (Introduction Act \$25. 2007). The participants may apply for supplementing aid for special purposes, such as medicine and healthcare, transportation and moving (Kavli and Djuve 2007) All participants in the introduction programme are eligible for the benefit (Introduction Act §8. 2007). Moreover, in Norway the allowance can be combined with work; in Denmark the introduction allowance is cut off when the participant finds an ordinary job or starts regular education. The participants in the Norwegian introduction programme maintain the whole introduction benefit when he/she is in a full-time programme (Kavli and Djuve 2007).

In both countries the future payments are deducted based on hours of absence from the introduction programme (ibid). However, the Danish financial sanctioning goes far beyond what can be legally carried out in Norway. Since the introduction benefit is evaluated with respect to both spouses in Denmark married couples have a common responsibility for participating. Unless both spouses participate in the programme, meet for a job- or CV-conversation, or a disposal evaluation, and report themselves as jobseekers at Jobnet, their benefit will be reduced (Integration Act \$28-31. 2008). In addition, the introduction benefit must be repaid if the immigrant fails to inform the relevant authorities that he/she has obtained a regular job (ibid §31a). This also affects the spouse.

In the Integration Act, we are introduced to the concept of integration councils and the Council for Ethnic Minorities (REM), which was established in 1999. The vice-chairman of REM explained in 2007 that there were more than $50^{18}$ integration councils in Denmark's municipalities. The integration councils provide the public with 'advisory opinions on the general effort of integration in the municipality and on the introduction programmes offered by the local council.' (Integration Act \$42-2. 2008). Every four years, members of the integration councils are elected for the REM (ibid: \$42-43). REM 'advises the Minister of the Interior on issues of importance to refugees and immigrants. The Council cannot submit opinions on individual cases.' (The Integration Act \$44-4. 2008). In Norway the Contact Council Between the Government and Immigrants (KIM) was founded in 2003. This is also an advisory council aiming at advocating immigrants' rights and facilitating dialogue. In Norway there were no statutory municipal integration councils at the time of the research ${ }^{19}$.

\section{The individual action plan and the language tests}

The individual action plan has been implemented as a tool for user participation throughout the Norwegian welfare system. Its main objective is to coordinate the services and make the service providers and the service user responsible for the goals in the plan. This action plan is a voluntary right for all persons using welfare services. However, according to the Introduction Act, the individual action plan is not optional for participants in the introduction programme (Introduction Act §6. 2007).

The individual action plan is a mutual agreement the municipality shall draw up in consultation with the immigrant. It must be reassessed at regular intervals and when significant changes must be made (ibid). The programme guides in the municipal refugee offices follow up the participants in the introduction programme and their individual action plans. Additionally, they cooperate with other partners (schools, health services and more) to 'open doors' for the immigrants regarding work practice among other things.

\footnotetext{
$18 \mathrm{http}: / /$ www.rem.dk/sw8154.asp

19 http://www.kim.no/templates/Hoeringsuttalelse.aspx?id=2115
} 
In Norway passing an integration test as such is not an explicit criterion for gaining a residential permit (Kavli and Djuve 2007). However, the permanent residence permit, and later Norwegian citizenship ${ }^{20}$, can be granted when the applier has been through 250 hours of language training and 50 hours of social studies. Also, in order to be accepted into the primary school level the participants must pass a language test on level 2. Passing a language test on level 3 was originally a condition for application to high school. According to the Norwegian language teacher, this practice has been changed, and the schools have their own test for introduction participants. The Bergen ${ }^{21}$ test is required for access to higher education.

\section{The Integration Contract and the Language Tests}

The judicial adviser at the Danish Integration Ministry explained that the individual action plan was changed to the Integration Contract in 2005. The information in the contract is quite similar to the Norwegian individual action plan, and it is followed up by the job centres in the municipalities every third month. In the integration contract there are goals and sub-goals, for instance concerning which Danish test one must pass as well as participation in work practice or education. In addition, the contract includes information on the consequences of the participant not fulfilling the criteria in the contract and passing the introduction programme language test within the three-year time limit. More than 15\% of non-documented absence from the programme will be sanctioned by reduction or withdrawal of the allowance, or even exclusion from the training. Moreover, 'Non-attendance in the introduction programmes without reasonable cause, can mean that the participant cannot attain permanent residence permit according to the Immigration act \$11-9.' (Integration contract). However, if the participants have passed a Danish test during the three years, it is regarded as completion of the programme, regardless of whether they have participated the full $85 \%$ or not. There are other exceptions to the $85 \%$ rule, for example serious illness or a heavy workload during this period. Giving birth gives a 12-month permission to be absent from the programme. Furthermore, people with no ties to the labour market, who are depending on welfare benefits, and who have lived in the country for a long time, can be offered participation in the 'New Chance' programme. The programme guide in Denmark claims that there are always possibilities in the education field for immigrants:

'For a person who still has education resources, and at some point stabilize their social and economic situation, we have a broad selection of adult education opportunities. And adults get a second chance. They can make use of these, all the time. There are always language schools that will accept them, there are always adult education centres where one can continue moving further, if one has ambitions of further education.'

The integration act says that by the end of the introduction period the local council draws up a final status regarding participation in the introduction programme and the fulfilled goals in the integration contract. This status is the foundation for the local council's statement to the Danish Immigration Service (Integration Act \$18. 2008). The Danish Immigration Service then issues an opinion concerning whether the immigrant in question has completed the introduction programme, including the date the integration contract was drawn up, when the foreigner signed the integration contract, and the declaration on integration and active citizenship in the Danish society (ibid: §52). The status and the opinion are issued so that the Danish Immigration Service can decide whether or not to grant the immigrant a permanent residence permit. This application is evaluated based on whether the immigrant has fulfilled his/her duties regarding participation in work training activities and the Danish language course, and whether he/she has passed the language test (ibid): The programme guide in Copenhagen explained that immigrants are not sent home if they do not pass the exams:

\footnotetext{
${ }^{20}$ www.imdi.no/no/Kvalifisering/Hovedprinsipper-for-ordningen/

${ }^{21}$ More about the Bergen test: www.fu.no/default.asp?avd=231\&nyh=5698
} 
'In Copenhagen municipality there has been an exception that even people in many years have not managed to finish their things; have had the opportunity to receive training in the Danish language free of charge.'

A teacher at IA private language centre in Copenhagen had a different opinion concerning the tests. He showed me one test example called 'Heavenly delight', where the topic was Christianity and religious people's good sexual habits. The language teacher said that these topics do not create an environment for good performance; topics such as religion, politics and sexuality can rather serve to provoke the participants. In an exam situation, everything should be aimed at facilitating the best possible performance. Furthermore, the teacher found it strange that most of the test for Danish 3 is on topics from women's magazines, pointing out that the candidates have often never seen a test the topic of which is cars or sports, and the upshot is that the men consistently underperform.

'The way I see it, there is a deliberate intention on the part of the Danish Ministry to make things as difficult as possible for foreigners, and they do, in reality, not pave the way for integration at all ... This is because our parliament wants foreigners out of the country ... The DPP has a hidden agenda, which is reflected in the test and everything else ... Luckily our participants are pragmatic. They are from surroundings where they are used to being pursued by an authority.'

\section{The declaration on integration and active citizenship in Danish society}

The declaration on integration and active citizenship in the Danish society is not a contract, but more an information sheet that must be signed so that the authorities can see that the immigrants are informed about Danish values. However, according to the Danish judicial adviser, if an immigrant postpones signing the integration contract and the declaration on integration and active citizenship, the opportunity to apply for the permanent residence permit will be postponed for a time period equivalent to the time used to sign the two documents. In this sense, although the declaration is not a contract, not signing it has just as strong juridical consequences as not signing the integration contract.

In the declaration there is a list of Danish values that immigrants must comply with if they want to be granted a residence permit of indefinite duration. In addition to understanding the importance of integration, responsible Danish upbringing, and tax payment, immigrants shall endeavour to become self-supporting. Furthermore, immigrants must 'understand and accept that it is illegal in Denmark to commit actual violence or threaten violence against one's spouse' and 'that it is illegal in Denmark to hit one's children' (Declaration of Integration), and also that the circumcision of girls and forcing contract marriages are illegal. The Danish fundamental constitutional rights must be respected; gender-equality, freedom of speech and religion, and the personal integrity of the individual are examples listed in the declaration. It is also pointed out that 'threats and scorn against groups on the grounds of religion or sexual orientation is illegal in Denmark' (ibid). Immigrants must understand and accept 'that Danish society strongly condemns acts of terrorism' (ibid) and they are obliged to assist the authorities in the prevention and investigation of and the fight against terrorism. Criminal offences may postpone or prevent the issuing of a permanent residence permit, and it must be understood and accepted that 'if I am a refugee I am no longer entitled to protection if the conditions in my home country have changed to the effect that I can return' (ibid). Moreover, refugees must declare that they understand and accept that returning with their families to their original home country or previous country of residence will be awarded with financial support (ibid). 
The declaration has been criticised by, among others ${ }^{22}$, Kamal H. Qureshi of the Danish Socialist People party. He thinks that the declaration is demeaning and patronising, and that the Danish government is throwing suspicion on immigrants ${ }^{23}$. He considers the criteria in the declaration to involve an extremely negative labelling of immigrants ${ }^{24}$ (K. Qureshi 2005). When the deputy chairman of the REM was asked about his thoughts on the integration contract and the declaration of integration, he replied that making such a contract is an unfair way of treating people. Many immigrants have in fact left Denmark after reading this contract.

'I think the politicians and local communities must work to win the foreigners' hearts. In many ways ... it IS actually (bureaucratic); it does not facilitate integration, it gives a negative people look negative at it ... I mean, we are not entering the military.'

\section{Trust Development in Integration Practice}

When exploring perspectives on integration practice and the concept of integration itself, my ambition has been to analyse trust development in integration practice. Below, there is an illustration of the ways distrust and trust can have an impact on immigrants' opportunities, inspired by Lewicki et al.'s (2006) transitional trust models. I have added exclusion, assimilation, integration and inclusion as corresponding categories to distrust and trust in the model. I do not claim that these categories should be regarded as pure and rigid; in fact, they can overlap.

\section{Exclusion}

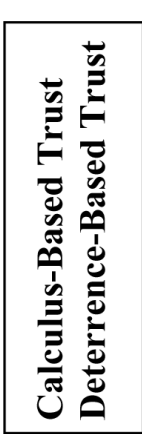

Assimilation

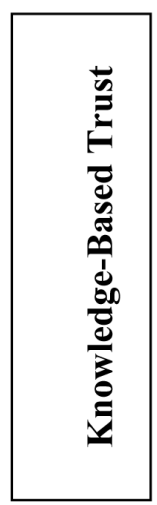

Integration

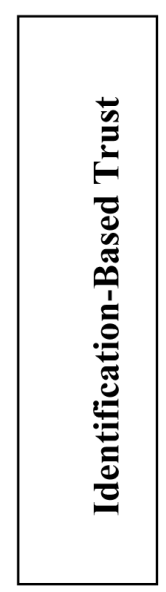

Inclusion

Figure 1: Model of trust development in integration practice

\section{Exclusion and calculus-based trust}

Immigration legislation defines who can be granted asylum (Foster 2007: the Schengen Agreement, the Dublin Convention) and residence permit, and the EEA defines who can move freely and work within the EEA-area. The UN definition of refugees give refugee status to people in need of protection against persecution. In addition, as we have seen, the Integration Act and the Introduction Act apply to groups that are obliged to and have the right to participate in the introduction programmes. Also, not signing the contract and the declaration excludes immigrants from the introduction programme and postpone their opportunity to gain a permanent residence permit in Denmark. These definitions and regulations formally determine who can be selected and recognised for the 'inside', and they are clear examples of the fact that inclusion relies on the possibility to exclude. 
One of the inclusion-terms to accessing Denmark and Norway is that you are 'integrable'. Both Denmark and Norway primarily define integration in their legislation and elsewhere as being able to make a contribution in the labour market. Moreover, for many migrants who cannot meet this overall inclusion term (except refugees), it seems as though the government will not allow them past the first wall of trust, calculus-based trust. However, if they can be expected to follow the playing rules for a functional differentiated society, the government will allow the integrable immigrants access, because they can be trusted to seek jobs.

It is fair to assume that the government and the immigrants have mutual interests insofar as the immigrants have also calculated their gains by crossing these borders, and they trust that they will find work, education, and better opportunities. Expecting immigrants to endeavour to become self-supporting is a clear-cut CBT-statement in the declaration and in the Introduction Act. However, CBT is also about calculating risks. The immigrants risk becoming unemployed, which means that these welfare states have a responsibility to provide for them, and the government has calculated the risk of social consequences such as unemployment. From this research it is difficult to determine to what degree immigrants have calculated this risk. It is, however, an interesting issue: Do immigrants have realistic expectations concerning the opportunities in the receiving country?

Having said that, many may find the opinions of the language teacher at IA radical when he explained his views concerning the tests', the DPP's and the Ministry's agenda for more or less excluding male immigrants. However, the declaration of integration and the test example show some less hospitable aspects of the integration practice in Denmark. When studying the declaration, I found that the statements there illustrated a high level of distrust towards the signing party. It is difficult not to interpret these incentives as prejudice towards targeted groups in the immigration population. Some would say that the declaration implicitly claims that the Danish upbringing is the right way to rear children. Furthermore, the declaration is explicit about what is illegal in Denmark, and that these activities will be punished. Finally, pointing out that if the immigrant has a chance to return to his/her country of origin, he/she will be rewarded with financial support cannot be misinterpreted. These statements can all be viewed as excluding, in the sense that they do not appear to respect and socially recognise the persons who have not yet been selected to be included among the inner side. In fact, the formulations in the declaration seem to aim at sieving out the 'non- integrable'.

Luhmann points out that social cohesion is revealed by the existence of the non-integrable. In their report on social cohesion (2008) the Council of Europe pointed out that many associate this term with a society's connectedness 'when individuals and groups feel common cause with others ${ }^{25}$. People who see themselves as members of a community can recognise, and are prepared to act for the collective good. My impression is that the declaration itself does not communicate values that commit to a unifying society in its excluding and deterrent formulations. However, social cohesion is also about people being able to participate in and enjoying the advantages of economic life, among other things (ibid). Hence, it would be wrong to make claims to the effect that the integration programmes do not promote social cohesion.

\section{Deterrence-based trust and assimilation}

Agreeing with Carrera and Brubaker's statements, Qureshi and Hagen have argued that assimilation is referred to as 'integration'. In Norway the more 'Norwegian' an immigrant has become, the more he/she is regarded as successfully integrated. Integration has really been a matter of assimilation; the minorities relinquish their own culture in order to adapt to the majority culture (Qureshi and Hagen 1996:16). However, Brubaker claimed that it is no longer

\footnotetext{
${ }^{25}$ http://www.coe.int/t/dg3/socialpolicies/source/TFSC(2007)31E.doc:p.8
} 
true that people are expected to assimilate; rather the core meaning of 'assimilation' now is 'increasing similarity or likeness'.

My interpretation is that the Danish government expects immigrants to accept a form of forced assimilation; if they do not sign the contract and the declaration, they are not allowed to start the introduction programme. Regarding the integration contract and the declaration of integration it seems as though the Danish government expects immigrants to be mouldable and meltable objects, and that they must play by the government's rules. Now, when suggesting that the Danish government wishes to make immigrants more similar by endorsing the formulations in the declaration, I do not imply that it rather should be indifferent and tolerate everything. My point is that when signing such a document, immigrants are forced into a stereotype, which may be easier to mould into what is defined as Danish.

As we know, deterrence-based trust is about preventing or discouraging distrustful acts. Now, informed migrants going to Denmark may have calculated with their being exposed to the assimilation pressure in a new society. Are they, however, prepared to accept what K. Qureshi defines as patronising and demeaning descriptions, and do they calculate with being met with the distrustful formulations in the declaration? Regarding the integration contract, the declaration and the Danish language test, Brubaker's words about the 'old' assimilation comes to mind. In the declaration, the Danish government has formulated their distrustful expectations of immigrants, in addition to their expectations of how the immigrants must attain a particular degree of similarity to the Danish values. Moreover, as the language teacher suggests there are parallels between these practices and the DPP's party program ${ }^{26}$. Here there are statements about the importance of preserving and protecting the Danish culture, avoiding the transformation to a multiethnic society, and honoring Christianity as the national religion.

Now, the individual action plan in Norway may also be regarded as a kind of forced assimilation. To people that do not have the same relationship to bureaucracy as Scandinavians, the plan may be perceived as something they are forced to value and live by. However, the individual action plan is not forced assimilation to the same extent as the integration contract and the declaration. Even though the individual action plan is obligatory for participants in the introduction programme, the municipalities in Norway cannot make it without cooperating with the participants. In this regard the immigrant is treated as an active subject who can choose to participate, and, as we know, these are definitions Brubaker has used regarding the returned assimilation. Assimilation in this sense is also a matter of treating persons as similar, and it does not agree with discriminating practice. However, examples of discrimination can be found in both introduction programmes: In Norway participants in the programme are the only ones in the welfare system who must draw up the action plan; in Denmark both the introduction allowance and the fact that spouses can be financially sanctioned have been regarded as discriminating.

I have claimed that the integration contract, the declaration of integration, the test-example from IA and the individual action plan are assimilating. However, I find that assimilation in Denmark and Norway also has a general and abstract manner. I interpret Brubaker's definitions of the 'returned assimilation' as being very close to the integration term used by Qureshi and Hagen. Focusing on the process of increasing degrees of similarity or likeness may just as well be focusing on the degree to which an individual can live up to the group's norms. Nevertheless, transitive assimilation does not recognise diversity without suppression, obliteration and subjection, and does not give everyone the same chance to influence their environment. Accepting ethnic groups for their diversity and supporting their distinctive

\footnotetext{
${ }^{26} \mathrm{http}: / /$ www.danskfolkeparti.dk/The_Party_Program_of_the_Danish_Peoples_Party.asp
} 
character is not what this kind of assimilation is about. In this sense, it would be highly unfair to categorise the Norwegian and the Danish integration practices as only assimilative.

I find that assimilation in a deterrent way is not about basing trust on mutual knowledge and understanding. Rather, it is a matter of one party being able to make the other party's values, definitions, behavioural codes and views similar to its own. However, the relationship in these assimilative practices is one-sided and focused on maximising self-interest. Now, Carrera argues that integration is a one-way process; immigrants have the responsibilities and duties on their side only. They are forced to integrate (assimilate) so that they can be treated as members and access a secure juridical status (Carrera 2006/1). This view agrees with many of the reflections on the integration contract, declaration and action plan. However, in both countries the municipalities are obliged to provide the services in the introduction programme. Integration is therefore not just a duty but also a right. In fact, the REM Deputy Chairman points out that few countries provide equally good offers to immigrants.

\section{Knowledge-based trust and integration}

In the EU Hague Program, and in the Danish and Norwegian legislation, the principle of integration as a two-way process is highly prioritised. To accomplish this it seems that the key is to allow both immigrants and the residing population to engage in activities that generate KBT. This is not only a matter of making immigrants able to understand and predict behaviour in the Danish and Norwegian societies, but also to enable others to understand and predict their behaviour. This is why work practice, mentors and admittance to the labour market for the purpose of enabling relations to develop beyond calculating gains and costs are so important in the introduction programmes.

On the one hand, a holistic perspective on integration is formulated the Integration Act. The integration effort is not just the governments' responsibility. Encouraging the rest of society to contribute makes integration in principle a two-way process. Furthermore, establishing advisory councils in Denmark and Norway that represent the immigrant population encourages dialogue and shows that that the integration practices in the two countries can be two-way. Advisory councils where representatives from the government and the immigrant population meet also increases mutual KBT between the government and minorities. In addition, the governments subsidise a mentor-agreement ${ }^{27}$ at the workplace. When an immigrant participates in work practice in order to practice the language, the workplace may provide a mentor who closely follows up the participant. On the other hand, with regards to the IA teacher's reasoning about the language tests one may ask where the cultural sensitivity is in introducing delicate topics such as religion, sexual habits and politics in this pressured situation. Furthermore, the way I see it, cultural competence is not only a matter of knowledge about ethnic groups. It is also a matter of targeting the tests towards men and women, and acknowledging and respecting that the genders have different points of reference.

Having said that, the introduction programmes, particularly the language training, work practice, and employment-with-wage-subsidy are well known integration efforts aimed at making society accessible. Work practice is the most used strategy for integrating individuals into the labour market (Djuve 2007). However, Djuve argues that the effect of work practice is positive but moderate. Studies in Denmark describe the employers in Danish workplaces as more positively inclined towards hiring immigrants on ordinary terms. The employers actually 'have limited enthusiasm' regarding employing immigrants with wage subsidies or other types of assistance from the public (ibid:13; IFKA 2006). Equivalent views have been found in Norwegian

${ }^{27}$ Information is collected in the booklet about the mentor agreement: 'Få tilskud til en Mentor- det ender med at blive en god investering' 
studies. Barely any of the private businesses in Norway were interested in advice about subsidy arrangements and follow-up from the municipalities. However, around 20\% wanted advice on how to evaluate competence (ibid; IMDi 2006). In fact, most of the interviewees agreed that one of the most dominant obstacles for highly skilled immigrants was translating and assessing the foreign levels of education in terms of the Scandinavian standards. Djuve concludes that businesses primarily want immigrants who are self-sufficient. Since participation in this form of activation can be stigmatising (ibid), I find that work practice, wage subsidies and an insufficient competence-evaluation system can also be regarded as excluding.

In Denmark and Norway language training is regarded as the most efficient way to integrate immigrants into the workforce. In Norway, the subject specific language training was asked for but not yet provided in 2007. Denmark provides the specialised subject knowledge that is required in a functionally differentiated society. When immigrants have the possibility to practice subject-specific skills and develop social and cultural competence, they also get a chance to move from CBT to KBT. The focus then changes to an emphasis on assimilation between oneself and others. In fact, enabling immigrants to specialise their career is not only integrating but a recipe for societal inclusion.

\section{Identification-based trust and inclusion}

When knowledge about the other makes the individuals identify with and care for each other, the trust in the relationship has evolved into IBT. A transformation of motivation has shifted the orientation, from 'a focus on maximizing self-interest to a disposition toward maximizing joint outcomes' (Lewicki, Tomlinson and Gillespie 2006:1012; Lewicki and Bunker 1995,1996). When a family or an individual wants to be included in the local community, neighbourhood activities such as sports or children's upbringing can be the common grounds. By participating on these arenas one can achieve the benefits of being social with friends, and also increase social capital through building a network. When IBT has been reached, the relationship consists of common products and goals, and shared values. Participation in the introduction programmes can make the labour market and neighbourhood arenas more accessible and thereby promote further social inclusion. Also, understanding the local language and customs, interpreting the meaning behind actions and knowledge of the receiving society's common logic are necessary conditions for participating in society. Consequently, the knowledge gained in the language training, social studies and work practice, in contact with fellow students, mentors or teachers, is important for social inclusion.

\section{Concluding remarks}

What has been learned about integration and trust from this comparison between integration practices in Denmark and Norway? This comparative study of theory and practice has provided knowledge concerning integration that can also apply to other relevant fields such as schooling, rehabilitation, addiction treatment, mental health and more. Furthermore, comparing these theories, and comparing them with the empirical data has clarified how important trust is in the integration process, and it has enabled a natural categorisation. On the other hand, challenging the understanding of integration as a concept has made it evident that the term is multi-sided and difficult to rigidly limit to one category. Looking at the practices in introduction programmes has contributed to obtaining an understanding of this multisidedness. Integration is more than a mutual process where unifying parts can both keep their origin and adopt new qualities from each other.

This study shows that integration practices in Denmark and Norway can be excluding, assimilating, integrating and including. In addition, it shows that trust and distrust development has an impact on immigrants' access to society. By this I mean that persons are exposed to the 
highest level of distrust when they are unable to cross the borders of a country. In addition, the deterrence-based trust shown in the Declaration of Integration is not exactly welcoming; rather, it clearly shows distrust towards immigrants. However, if a person is integrable, calculus-based trust is developed and the person can access the opportunities in the introduction programme, in education or in the labour market. Furthermore, the trust-development reaches a whole new level when people can mutually interact and get to know one another. As we have seen, once the knowledge-based trust-level is reached it becomes easier for immigrants to attain identification-based trust and thereby to integrate and become socially included. It is an interesting paradox that when persons reach knowledge-based trust, the majority society is actually in the best position to learn more about them. Ironically, this knowledge would enable the socially recognised 'inner side' to challenge the stereotyping that initially excludes 'outer side'-persons from participating in and enjoying the advantages of society.

\section{References}

- Brubaker, Rogers (2001): The return of assimilation? Changing perspectives on immigration and its sequels in France, Germany, and the United States. Ethnic and Racial Studies Vol. 24 No. 4 July 2001 pp. 531-548. UK: Taylor \& Francis Ltd

- Esping-Andersen, Gøsta (1990): The Three Worlds of Welfare Capitalism. Cambridge: Polity.

- Foster, Nigel G (2006): Blackstone's EC LEGISLATION 2006-2007 $17^{\text {th }}$ Edition. Oxford: Oxford University press.

- Hagen, Gerd and Qureshi, Naushad Ali (1996): Etnisitet i sosialt arbeid: Arbeid med etniske minoriteter i barnevern og sosial sektor. Oslo: Tano Aschehoug

- Larsen, Tone (2008): A comparative study of integration in a western context, between the introduction programmes in Denmark and Norway. Master dissertation, Høyskolen i Bodø.

- Magnus, Gunnar (11.10.06): Frp vil ha samfunnstest for henteektefeller: Dagbladet

- Nugent, Neil (2006): THE GOVERNMENT AND POLITICS OF THE EUROPEAN UNION. New York: Palgrave Macmillan.

- Peters, B. Guy (1998). Comparative politics: Theories and methods. Basingstoke, UK: Palgrave.

- Puntervold, Bente Bø (2002): Immigration Control. Law and Morality Visa Policies towards visitors and Asylum seekers. An evaluation of the Norwegian Visa Policies within a Legal and Moral Frame of Reference. Oslo: Unipub forlag

- Ragin, Charles (1987): The comparative Method. Moving beyond Qualitative and Quantitative Strategies. California: University of California Press

- Storhaug, Hege (10.06.07): Et politisk selvmord: Dagbladet

\section{Webpages:}

- http://home.online/ nqureshi/Kronikker/30.htm: Qureshi, Naushad Ali (1999): 'En vaksine mot FrPs premisser'

- http://jom.sagepub.com/cgi/content/abstract/32/6/991: Lewicki, Roy J., Tomlinson, Edward C. and Gillespie, Nicole (2006): Models of Interpersonal Trust Development: Theoretical Approaches, Empirical Evidence, and Future Directions. Journal of Management 2006; 32; 991.

- http://psc.sagepub.com/cgi/content/abstract/32/1/65: Braeckman, Antoon (2006): Niklas Luhmann's systems theoretical redescription of the inclusion/exclusion debate. Philosophy Social Criticism 2006; 32; 65

- http://www.ceps.be: Carrera, Sergio (2006/1): A Comparison of Integration Programmes in the EU Trends and Weaknesses. CHALLENGE Papers.

- Carrera et al (2006): The Nexus between Immigration, Integration and Citizenship in the EU. CHALLENGE Papers

- http://www.coe.int/t/dg3/socialpolicies/source/TFSC(2007)31E.doc: Council of Europe (2008): REPORT OF HIGH-LEVEL TASK FORCE ON SOCIAL COHESION. TFSC (2007) 31 E. 
- http://www.fafo.no/pub/rapp/20026/20026.pdf: Djuve, Anne Britt (2007): "Vi får to ekstra hender." Arbeidsgiveres syn på praksisplasser for ikke-vestlige innvandrere"

- http://www.idunn.no/content?marketplaceld=2000\&languageld=1\&contentltemld=176 8974\&pageName=printVersion\&siteNodeld=1769111\&skipDecorating=true: Qureshi, Naushad Ali (2005) "Profesjonell kultursensitivitet framfor faglig etnisentrisme" Helse og Sosialfag - Tidsskrift for psykisk helsearbeid - 2005 - Nr 03 -

- http://www.lovdata.no: The Immigration Act (2008)

The Introduction Act (2007)

- http://www.migrationinformation.org/Profiles/display.cfm?id=485: Hedetoft, UIf (2006) Denmark: Integrating Immigrants into a Homogeneous Welfare State.

- http://www.nrk.no/nett-tv/klipp/286328/: NRK 08.09.07: Valg 07: Partilederdebatten.

- http://www.nyidanmark.dk/en-us/legislation/legislation.htm: The Integration act in English

- http://www.nyidanmark.dk/NR/rdonlyres/BFD39DAB-9649-461D-8EB4-7353B2774139/0/ integrationskontrakt.pdf: The integration contract

- http://www.nyidanmark.dk/NR/rdonlyres/7A32FAD0-E279-467C-91E3-3074249ED586/0/ integrationserklaering_engelsk.pdf: Declaration on integration and active citizenship in Danish society

- http://www.regjeringen.no/Rpub/OTP/20052006/023/PDFS/OTP200520060023000DDDPDFS. pdf Ot.prp. nr. 23 Om lov om endringer i introduksjonsloven 2005-2006

- http://www.temaasyl.se/Documents/Övrigt/Integrering\%20i\%20Danmark\%20Sverige\%20o\%20 Norge.pdf: Djuve, Anne Britt and Kavli, Hanne Cecilie (2007): Integrering i Danmark, Sverige og Norge, Felles utfordringer - like løsninger? TemaNord 2007:575 Nordisk Ministerråd, København - http://www.ub.uio.no/cgi-bin/ujur/ulov/sok.cgi?type=LOV: The Introduction Act in English. 